\title{
Combinando Técnicas de Teste com Usuário e Julgamento de Especialistas na Avaliação de um Exergame para Estimulação das Funções Executivas
}

\author{
João Batista Mossmann - PGIE/UFRGS - mossmann@ feevale.br \\ Eliseo Berni Reategui - PGIE/UFRGS - eliseoreategui@gmail.com \\ Débora Nice Ferreira Barbosa - Universidade Feevale - deboranice@ feevale.br \\ Caroline de Oliveira Cardoso - PUCRS - carolineocardoso@ yahoo.com.br \\ Rochele Paz Fonseca - PUCRS - rochele.fonseca@ gmail.com \\ Bernardo Benites de Cerqueira - Universidade Feevale - bcerqueira@feevale.br \\ Ana Cervi Colling - Universidade Feevale - anapaula_cervi@ hotmail.com \\ Resumo. O presente artigo apresenta o Exergame "As Incríveis Aventuras de \\ Apollo e Rosetta no Espaço", focado na estimulação do desenvolvimento \\ cognitivo infantil no contexto das funções executivas, mais especificamente do \\ controle inibitório, para as crianças do Ensino Fundamental I. O artigo \\ também aborda o processo de avaliação prévia do jogo desenvolvido, antes de \\ sua utilização no ambiente escolar. $O$ processo de avaliação foi realizado em \\ etapas distintas, por meio da combinação de duas técnicas: uma etapa foi \\ julgada por especialistas em neuropsicologia e outra conduzida com um \\ usuário de mesma idade das crianças que participarão da intervenção futura. \\ Assim, este estudo avaliou e promoveu ajustes no Exergame, orientado pelos \\ dados obtidos durante o período de validação.
}

Palavras-chaves. Exergame; objetos de aprendizagem; informática na educação; funções executivas; jogabilidade;

Abstract. This article presents an Exergame called "The Incredible Adventures of Apollo and Rosetta in the Space (As Incriveis Aventuras de Apollo e Rosetta no Espaço)", a game that stimulates child cognitive development, more specifically the inhibitory control related to executive functions, aimed for children in elementary school. Moreover, the paper presents the process of previous evaluation of the developed game, before it's used in the school environment. The evaluation process was fulfilled in different stages, using two techniques: a judgement by specialists in neuropsychology and a user test conducted with one child with the same age as the children who will participate in the future intervention. Therefore, after analyzing the data obtained during the validation period, evaluations and adjustments were promoted in the Exergame.

Keywords. Exergame, learning objects; informatics in education; executive functions; playability;

\section{Introdução}

O artigo apresenta a avaliação de um jogo digital, aplicado no contexto educacional, para a estimulação das Funções Executivas (FE), mais especificamente do controle inibitório (CI), em crianças do Ensino Fundamental I. Como caraterística principal, 
destaca-se a utilização dos conceitos dos Exergames, em que o corpo é o elemento de interação entre o jogador e o jogo. Atualmente, o processo de desenvolvimento de jogos, educativos ou de entretenimento, é realizado por desenvolvedores de diferentes habilidades e formações. Assim, um jogo digital é um produto criativo, resultante de um esforço multidisciplinar aplicado no seu desenvolvimento. Dividem o desenvolvimento profissionais oriundos da Ciência da Computação, Design, Comunicação, Música, Jogos Digitais, além de especialistas do domínio, presentes principalmente no processo de desenvolvimento de jogos educativos.

No contexto deste trabalho, que procura avaliar um Exergame que realiza a estimulação do controle inibitório no ambiente escolar denominando "As Incríveis Aventuras de Apollo e Rosetta no Espaço", deve-se equacionar as necessidades técnicas do desenvolvimento com as determinações e formalidades do domínio, necessárias para atingir o objetivo de construir um jogo capaz de realizar a estimulação. Deste modo, a primeira avaliação descrita neste trabalho foi conduzida com especialistas do domínio (neuropsicologia) que inspecionaram o Exergame e buscaram identificar possíveis dificuldades que o público alvo poderia apresentar, bem como, avaliar se as mecânicas projetadas para o jogo exercitavam as FE.

Além da avaliação por especialistas, a equipe de pesquisa conduziu uma avaliação com um usuário utilizando o Exergame. Esta condição permitiu que a equipe registrasse os problemas, bem como os aspectos positivos, vivenciados através da experimentação do jogo. O principal objetivo da aplicação com o usuário foi observar questões relativas a jogabilidade. Assim, este artigo apresenta a combinação das técnicas de avaliação por especialista e por usuário, com o objetivo de inspecionar se o Exergame projetado é capaz de realizar o exercício das FE, bem como, avaliar se a jogabilidade é adequada às crianças do Ensino Fundamental I - público alvo do projeto.

Este artigo está dividido em seis seções. Na segunda é abordada a temática das Funções Executivas. Já a seção três apresenta o exergame "As Incríveis Aventuras de Apollo e Rosetta no Espaço" para estimulação das FE - controle inibitório. Na quarta seção são demonstrados dois tipos de avaliações realizadas: uma por juízes e outra pela observação de uma criança jogando. Na quinta seção, pode-se acompanhar os ajustes realizados nos mini-games de acordo com as avaliações recebidas, seguido das considerações finais, última seção do artigo.

\section{Funções Executivas}

Entende-se por Funções Executivas (FE) um conjunto de habilidades que tem como objetivo o controle e a regulação do comportamento a fim de atingir objetivos específicos. As FE são consideradas extremamente importantes para o desenvolvimento da criança, pois possibilitam (a) priorizar e iniciar um comportamento; (b) inibir uma resposta automática ou dominante; (c) manter a informação relevante na cabeça para finalizar uma tarefa; (d) resistir a distrações ou a estímulos irrelevantes; (e) criar diferentes alternativas para resolver um problema (DIAMOND, 2013). Desta forma, quando necessário, ou quando houver alguma atividade nova, as crianças recrutarão essas habilidades cognitivas, que requerem todas as habilidades citadas anteriormente, ou seja, quanto maior a complexidade e a necessidade de processamento controlado de estímulos não tão familiares. 
Nos últimos anos as pesquisas vêm demonstrando que diversos aspectos como competência no domínio social, emocional e escolar está vinculado a um nível elevado de funcionamento executivo (PINTO, 2008). Para o desempenho escolar, essas habilidades podem servir de base para o sucesso relacionado à leitura, à escrita e à matemática (BULL; ESPY; WIEBE, 2008; WELSH et al., 2010). É visto que as habilidades das FE podem fazer com que as crianças lidem melhor com seu ambiente, que está em constante mudança.

Atualmente, há um consenso entre pesquisadores dessa área que dividem as $\mathrm{FE}$ em três componentes principais. Diamond (DIAMOND, 2013) apresenta os seguintes componentes: 1) Memória de Trabalho; 2) Flexibilidade Cognitiva e 3) Controle Inibitório. Para alguns pesquisadores, o controle inibitório pode ser considerado como a habilidade de pensar antes de agir, de postergar ou inibir a resposta baseada na capacidade de avaliar múltiplos fatores. O componente inibição engloba as habilidades de controle inibitório e atenção seletiva, pois permite inibir a atenção a distratores, estimulando a autodisciplina e o autocontrole sobre a atenção e as ações tendenciosas ou reativas.

Pesquisas apontam que tais habilidades podem ser estimuladas e que a atividade física, por exemplo, melhora as FE. Diamond (2015) afirma que atividades físicas podem produzir uma melhora da cognição e da função cerebral, consequência da utilização do córtex pré-frontal do cérebro, área onde estão localizadas as FE. Há uma grande relevância destas habilidades quanto ao desempenho escolar, comportamento e, numa escala mais ampla, ao adequado funcionamento do indivíduo na sociedade, justificando assim, a ênfase internacional em procedimentos que estimulem seu desenvolvimento em crianças ainda em idades precoces.

\section{Exergame "As Incríveis Aventuras de Apollo e Rosetta no Espaço"}

Os Exergames podem ser considerados como uma classe de jogos que utilizam o movimento corporal como controle do jogo, ao invés de utilizar o joystick. Os movimentos corporais do jogador são interpretados como entrada de dados e associados a comandos/significados específicos para o jogo, transformando o movimento tridimensional do espaço físico, para uma entrada em sistema computacional (FINCO, 2015).

A tecnologia aliada ao exercício físico vem sendo estudada e tem apresentado resultados relevantes pois, além de estimular o corpo, estimula componentes executivos como memória de trabalho, controle inibitório, flexibilidade cognitiva, e funções mediadoras de seu desfecho. A utilização do Exergame tem servido como instrumento de apoio pedagógico, uma vez que foge da utilização de ferramentas padrões de ensino (ditas tradicionais). Há estudos que vinculam a utilização do Exergame a educação física, por exemplo (FINCO, 2015).

O desenvolvimento e a construção do Exergame "As Incríveis Aventuras de Apollo e Rosetta no Espaço", voltado para a estimulação das funções executivas, mais especificamente o controle inibitório, contou com uma equipe multidisciplinar, com pesquisadores e alunos de iniciação científica da psicologia, ciências da computação, pedagogia, informática aplicada à educação e jogos digitais. O jogo digital foi desenvolvido para Kinect e possui sete atividades diferentes, organizadas como minigames que possibilitam ao jogador lidar com eventos de controle inibitório. Cada 
atividade tem como foco um aumento contínuo e crescente de dificuldades executivas, iniciando por níveis mais fáceis. A seguir são mencionadas cada um dos mini-games presentes no jogo.

No mini-game Explorador a criança deve coletar diferentes objetos que aparecem flutuando em sua direção no cenário virtual, com o auxílio de uma lista que indica o que a criança deve ou não catalogar. $\mathrm{O}$ jogador deve apenas coletar os objetos indicados e desviar dos obstáculos que surgem no decorrer do jogo para vencê-lo. Este jogo trabalha o controle inibitório uma vez que a criança precisa inibir as respostas automáticas, pois deve manter-se concentrada, e não coletar os itens não relacionados. O objetivo do mini-game Decifrando Códigos é fazer com que o jogador pressione os botões que correspondem às letras que aparecem no painel de forma aleatória ou, quando for verbalizada uma palavra iniciada com uma dessas letras fixas, pressionar o botão em forma de estrela, localizado na parte superior da tela. Desta forma, há a estimulação do controle inibitório, pois deve conter o impulso de pressionar a letra que corresponde a palavra dita, apertando assim, o botão em forma de estrela.

Quanto ao mini-game Túnel Acelerador de Partículas, o jogador deve desviar dos obstáculos que aparecem na tela, sendo que durante a partida o jogador possui a visão do personagem de costas e, em momentos pontuais do trajeto, ele possui a visão frontal. Quando a visão inverte os direcionais permanecem os mesmos, o que faz com que os controle inibitório seja trabalhado, bem como, a flexibilidade cognitiva. Isso porque acaba exigindo que mantenha sua atenção e foco no personagem e há a quebra de um padrão de respostas automatizadas, a fim de desviar dos obstáculos. O minigame Pulando Asteroides possui como objetivo fazer com que o jogador pule em asteroides que acendem de acordo com as cores de uma "lista de cores" à esquerda. Caso os "asteroides" possuam a cor de acordo com aquelas presentes nessa lista, o jogador deverá pisar nos asteroides que não estão acesos, desta maneira, inibindo as respostas automáticas de pular nos asteroides com cores.

No Arte Galáctica é solicitado ao jogador que ele pinte uma tela com "bolinhas de tinta" que surgem, estourando-as e evitando as "bolinhas" de cor branca e/ou preta. Durante a partida aparece uma "mosca" na tela (projetada pelo computador) que funciona como um distrator para o jogador, pois ela dispara "bolinhas" pretas e brancas na tela, fazendo com que o jogador perca pontos. A estimulação do controle inibitório ocorre quando a criança evita estourar as "bolinhas" pretas e/ou brancas, mas também, quando surge a mosca e ela deve "segurá-la" para que não libere tais distratores. O Laboratório Estelar é um mini-game que cria a ideia de que o jogador está em um laboratório e deve preparar uma vitamina. É apresentado ao jogador quatro tubos transparentes que possuem cores e números correspondentes, sendo solicitado que pressione os botões de acordo com cada tubo quando a vitamina correspondente a cor e ao número aparecer. Com isso, o controle inibitório é estimulado, pois o jogador não deve pressionar os botões quando a "vitamina" não estiver correspondente ao tubo.

Por fim, o mini-game Desafio dos Opostos Cósmicos, possui dois personagens, "Tivo" e "Ovit", que fornecem informações sobre os objetos que o jogador deve coletar. Um dos personagens fala o que deve ser coletado e o outro fala o contrário, ou seja, o objeto que não deve ser coletado. Este mini-game estimula o controle inibitório, compreensão verbal do participante e a flexibilidade cognitiva, pois, além de inibir a 
resposta automática, o jogador deve fazer o oposto ao solicitado quando aparecer o personagem indicado.

\section{Avaliação}

Com a finalidade de validar a jogabilidade, além de verificar se os jogos são capazes de realizar a estimulação das FE pretendidas, foram realizadas duas avaliações distintas, sendo uma de jogabilidade e outra com juízes especialistas do domínio. A atividade com os juízes especialistas foi realizada primeiro e, em seguida, as sugestões advindas desta primeira avaliação foram implementadas no Exergame. Então, após o término deste desenvolvimento, foi realizada a avaliação com uma criança utilizando o jogo para avaliar a jogabilidade. Quanto aos aspectos éticos é importante mencionar que o projeto descrito neste artigo foi avaliado pelo comitê de ética com parecer favorável. As subseções a seguir descrevem esses dois momentos de avaliação.

\subsection{Análise de Juízes Especialistas}

A fase de análise por juízes especialistas foi realizada junto à dois profissionais com experiência em neuropsicologia, onde cada atividade do jogo foi avaliada por estes. Quanto a experiência na área de especialização, o Juiz A possui 9 anos de experiência, já o Juiz B é especialista há 13 anos. A avaliação dos juízes ocorreu na sala do Grupo de Pesquisa Neuropsicologia Clínica e Experimental da PUCRS. Primeiro, foi realizada uma apresentação e demonstração de cada uma das atividades presentes no jogo para os juízes. A avaliação foi gravada em áudio e, após a avaliação, cada comentário sobre os jogos foi cuidadosamente analisado e discutido com a equipe de desenvolvimento. Houve algumas reformulações, descritas na seção de resultados.

Além disso, os juízes avaliadores receberam um instrumento dividido em duas etapas. Uma etapa tinha como objetivo verificar qual a Função Executiva (Memória de Trabalho - MT, Controle Inibitório - CI e Flexibilidade Cognitiva - FG) o juiz julgava predominante em cada um dos sete mini-games. A outra etapa consistia em questionar os juízes sobre 3 diferentes temas alusivos a cada uma das sete atividades (mini-games) e sobre a narrativa lúdica criada, especificamente, para explicar o que é o controle inibitório às crianças participantes do projeto. Assim, as questões apresentadas aos juízes eram: 1) As descrições e instruções estão claras; 2) Atividades adequadas para crianças do público alvo e 3) Há coerência entre a atividade (mini-game) e o objetivo.

As respostas sobre as questões destacadas ocorriam através do julgamento em escala de 0 até 5 , onde 0 - discordo totalmente, 1 - discordo, 2 - discordo parcialmente, 4 - concordo, 5 - concordo totalmente. Neste contexto, para calcular a concordância dos julgamentos dos dois juízes, aplicou-se o índice Kappa (FONSECA, 2013), representado pela seguinte fórmula: $\mathrm{k}=(\Sigma \mathrm{fa}-\Sigma \mathrm{fe}) /(\mathrm{N}-\Sigma \mathrm{fe})$, na qual $\Sigma$ fa é o somatório do acordo observado entre os dois juízes. Já o $\Sigma$ fe é o somatório devido ao acaso. $\mathrm{O}$ emprego do índice nos dados coletados é apresentado na seção 5.

\subsection{Avaliação da Jogabilidade}

Para avaliar a jogabilidade do Exergame foi realizada uma aplicação piloto, de 5 sessões, com uma criança que nunca teve contato com o projeto ou mesmo com o jogo, a criança participante é um menino de 10 anos de idade. 
A avaliação empírica, utilizando de uma variação do método de Think Aloud (LEWIS, C., 1982), possibilitou verificar a curva de dificuldade dos jogos, que traça o quão complexa cada atividade tende a ficar conforme o jogador progride entre os níveis, bem como, uma averiguação acerca das regras e das narrativas, observando se elas eram assimiladas pela criança. Além disso, foi possível detectar possíveis problemas técnicos que deveriam ser resolvidos. As aplicações ocorreram em cinco sessões de uma hora de duração, sempre às quartas-feiras, sendo uma vez por semana, no horário das 18h30min. Todas as sessões foram registradas em vídeos (por duas câmeras e a captura de tela do jogo para que fosse possível acompanhar o desempenho da criança) e acompanhadas de pelo menos dois membros da equipe de desenvolvimento. Cada uma das sessões de avaliação possuía como objetivo principal testar todas as jogabilidades presentes no jogo. Enquanto esse processo ocorria, o jogo era alterado com base nas observações do teste realizado na semana anterior. Assim, na primeira aplicação do jogo, a equipe explicou brevemente à criança o intuito do projeto, as atividades previstas para o dia e o cronograma dos próximos encontros.

Em seguida foi realizado o cadastro da criança no jogo e foram apresentadas duas cenas de narrativa lúdica presentes no jogo, contextualizando o universo ficcional. Em seguida, foi exibida a parte da narrativa que aborda questões referentes ao Controle Inibitório. Calibrou-se o Kinect para a altura da criança, de modo a proporcionar a experiência de jogo adequada. Devido ao tempo limitado para a aplicação, não foi possível à criança experimentar todas os sete mini-games, porém, todas as narrativas foram exibidas. Neste primeiro dia, as atividades escolhidas para jogar foram: Explorador, Pulando Asteroides e Laboratório Estelar.

Entre a segunda e a quarta sessão, a criança pôde sempre jogar todas as setes atividades, por pelo menos cinco minutos cada. Também era permitido que acessasse o tutorial do jogo sempre que necessário. Na quinta e última sessão da aplicação piloto, as sete atividades foram novamente jogadas pela criança. Ao final, após todas as atividades terem sido experimentadas, foi exibida a cena de narrativa do Encerramento, onde é dado o contexto de fechamento do jogo, a fim de entregar a criança uma sensação de conclusão e de dever cumprido. Esta sessão deu fim à etapa da aplicação piloto. Ao longo das semanas foi possível perceber uma melhora no desempenho da criança nas atividades do jogo, o que se caracterizou pela redução na quantidade de jogadas erradas, ainda que a dificuldade estivesse crescendo progressivamente.

\section{Resultados das avaliações}

Esta seção apresenta os resultados das avaliações realizadas pelos juízes e pela observação da jogabilidade da criança enquanto realizada a utilização do jogo.

\subsection{Análise de Juízes Especialistas}

A Tabela 01 demonstra qual a FE os juízes julgavam predominante em cada uma das sete atividades (mini-games). Pode-se observar que há concordância dos juízes que as atividades estimulam o CI, exceto na atividade "Decifrando Códigos", onde um avaliador indicou MT como FE predominante e, outro, CI.

No primeiro questionamento sobre se "As descrições e Instruções estão claras" em cada uma das atividades, pode-se observar na Tabela 02 que não ocorreu uma concordância entre os juízes somente na atividade (mini-game) Decifrando Códigos. 
Assim, a Tabela 03 demonstra o resumo do índice Kappa desta atividade. Os valores das células diagonais indicam o número de observações de concordância entre os dois juízes. Então, nas demais células estão contidas as discordâncias. Já o total de frequências esperadas (devido ao acaso), obtém-se somando as multiplicações entre o total da linha pelo total da coluna correspondente e, então, dividindo-se esse produto pelo total de observações, logo:

- Somatório de fa $=5+1+1=7$

- Somatório de $\mathrm{fe}=((0 \times 0) / 8)+((0 \times 0) / 8)+((1 \times 1) / 8)+((2 \times 1) / 8)+((6 \times 5) / 8)=4,125$

- Cálculo de Kappa: (7-4,125 ) / (8-4,125) = 0,74

Tabela 01 - FE predominante na atividade de acordo com os juízes.

\begin{tabular}{|r|l|l|l|}
\hline Sequência & Mini-Game & Juiz A & Juiz B \\
\hline 1 & Pulando Asteroides & CI & CI \\
\hline 2 & Decifrando Códigos & MT & CI \\
\hline 3 & Túnel Acelerador de Partículas & CI & CI \\
\hline 4 & Explorador & CI & CI \\
\hline 5 & Arte Galáctica & CI & CI \\
\hline 6 & Laboratório Estelar & CI & CI \\
\hline 7 & Desafio dos Opostos & CI & CI \\
\hline
\end{tabular}

Conforme destacado em (FONSECA, 2013), quando o valor de Kappa fica entre 0.40 e 0.75 o acordo entre os juízes pode ser considerado "satisfatório a bom". Cabe ressaltar que o valor calculado nesta questão ficou próximo de 0.75 , já considerado excelente.

Tabela 02 - Concordância entre os juízes referente - pergunta 1

\begin{tabular}{|l|r|r|}
\hline Atividade & Juiz A & Juiz B \\
\hline Narrativa & 5 & 5 \\
\hline Pulando Asteroides & 3 & 3 \\
\hline Decifrando Códigos & 5 & 4 \\
\hline Túnel A. de Partículas & 5 & 5 \\
\hline Explorador & 5 & 5 \\
\hline Arte Galáctica & 5 & 5 \\
\hline Laboratório Estelar & 5 & 5 \\
\hline Desafio dos Opostos & 4 & 4 \\
\hline
\end{tabular}

Já no segundo e terceiro questionamentos, sobre se os mini-games (atividades) são, respectivamente, "Adequados para crianças do público alvo" e se "Há coerência entre a atividade e objetivo", é possível observar que os juízes concordaram em todas as questões, atribuindo o valor 5 - Concordo totalmente. Estes valores são apresentados nas Tabela 04 e Tabela 05.

Tabela 03 - Índice Kappa: 0,74 de concordância entre juízes na pergunta 1

\begin{tabular}{|c|c|c|c|c|c|c|c|}
\hline & & & & $\begin{array}{l}\text { Juiz B - } \\
\text { Respostas }\end{array}$ & & & \\
\hline & & R 1 & R 2 & R 3 & R 4 & R 5 & Total \\
\hline \multirow{6}{*}{$\begin{array}{l}\text { Juiz A } \\
\text { Respostas }\end{array}$} & R 1 & & & & & & 0 \\
\hline & R 2 & & & & & & 0 \\
\hline & R 3 & & & & & & 1 \\
\hline & R 4 & & & & 1 & & 1 \\
\hline & R 5 & & & & 1 & 5 & 6 \\
\hline & Total & $\overline{0}$ & 0 & 1 & 2 & 5 & 8 \\
\hline
\end{tabular}


Quando calculado o índice Kappa geral, ou seja, considerando todas as questões e respostas reunidas, o valor resultante é de 0,78. Isso indica uma excelente concordância entre os juízes (FONSECA, 2013). Assim, após a análise da ponderação dos juízes e do áudio que registrou a sessão de avaliação, a equipe de desenvolvimento do projeto realizou uma série de adequações nos jogos, que serão descritas a seguir.

Tabela 04 - Resposta dos juízes - pergunta 2 demonstrando 100\% de concordância

\begin{tabular}{|l|r|r|}
\hline Atividade & Juiz A & Juiz B \\
\hline Narrativa & 5 & 5 \\
\hline Pulando Asteroides & 5 & 5 \\
\hline Decifrando Códigos & 5 & 5 \\
\hline Túnel A. de Partículas & 5 & 5 \\
\hline Explorador & 5 & 5 \\
\hline Arte Galáctica & 5 & 5 \\
\hline Laboratório Estelar & 5 & 5 \\
\hline Desafio dos Opostos & 5 & 5 \\
\hline
\end{tabular}

Tabela 05 - Resposta dos juízes à pergunta 3 demonstrando $100 \%$ de concordância

\begin{tabular}{|l|r|r|}
\hline Atividade & Juiz A & Juiz B \\
\hline Narrativa & 5 & 5 \\
\hline Pulando Asteroides & 5 & 5 \\
\hline Decifrando Códigos & 5 & 5 \\
\hline Túnel A. de Partículas & 5 & 5 \\
\hline Explorador & 5 & 5 \\
\hline Arte Galáctica & 5 & 5 \\
\hline Laboratório Estelar & 5 & 5 \\
\hline Desafio dos Opostos & 5 & 5 \\
\hline
\end{tabular}

A atividade Pulando Asteroides, com nota baixa na questão que busca avaliar se as instruções estão claras para o aluno (conforme a Tabela 02), demandou ajustes no tutorial do jogo, onde foi necessário alterar a palavra "pisar no asteroide" para "pular no asteroide", visando especificar a ação da criança de não só mexer as pernas, mas pular em direção à cor solicitada. Ainda nesse tópico, foi modificada a ordem de apresentação dos elementos: asteroides e painéis de cores. Além disso, foi adicionado um vídeo demonstrativo de uma criança pulando nos asteroides de acordo com as cores certas. No momento seguinte, após apresentar o painel de cores erradas e os asteroides com as cores respectivas, mais um vídeo demonstrativo é proposto, de uma criança pulando nos asteroides sem cor, tal como deve ser realizado durante o jogo. No tutorial, há também um aumento da escala de asteroides coloridos, visando exaltar a cor presente nele. Além disso, os juízes indicaram colocar este jogo como quarto jogo a ser exercitado pelos alunos durante a estimulação cognitiva, pela complexidade envolvendo a jogabilidade.

Também o jogo Desafio dos Opostos, com uma nota baixa referente as instruções, passou por modificações, onde foram adicionadas animações ilustrativas do jogador realizando a ação de coletar o item correto e um de coletar o item oposto ao solicitado. Também novas falas (dos personagens) foram inseridas para ilustrar e deixar claro como são solicitadas as coletas. Houve uma discordância entre os juízes na atividade Decifrando Códigos, quando questionados sobre as instruções do jogo. Assim, neste jogo foi adicionada uma animação no tutorial que ilustra a ação do jogador - apertar o botão solicitado e apertar o botão especial, deixando mais evidente a ação que o jogador deve realizar quando solicitado. Conforme a análise do áudio dos juízes, o tutorial da atividade Túnel Acelerador de Partículas foi melhorado, visando demonstrar de forma mais clara o momento de inversão de câmera e comandos. 
Assim, também o Explorador Espacial ganhou dois novos vídeos no tutorial, para elucidar a ação do jogador de coletar itens com as mãos esquerda e direita, e outra que demonstra como superar obstáculos presentes no jogo. Ainda, conforme destacado pelos juízes, devido a facilidade de entender esta atividade, ele passa a ser o primeiro a ser aprendido na lista de seleção de jogos, trocando de lugar com o Pulando Asteroides. $\mathrm{Na}$ atividade Arte Galáctica, no tutorial, foi adicionada uma animação ilustrativa para que a criança entenda a ação de parar a mosca, bem como o movimento da mão para acertar a bolinha. Conforme observado no áudio dos juízes, na atividade Laboratório Estelar devia ser melhorada a explicação da ação, sendo adicionados vídeos que ilustram o momento de coletar a vitamina e o momento de não coletar.

\subsection{Avaliação da Jogabilidade}

Finalizado a sessão de aplicação de teste de usuário com a criança, os vídeos coletados, bem como o gravado através da captura de tela, foram sincronizados em um único vídeo, para auxiliar na interpretação dos eventos ocorridos durante o teste. Assim, podese observar no mesmo instante as imagens da tela do jogo e das câmeras. A equipe de desenvolvimento reunia-se para analisar toda a experimentação gravada, registrando as ocorrências e viabilizando as modificações e correções necessárias (MOSSMANN, 2017).

$\mathrm{Na}$ segunda e na terceira sessão foi preciso reforçar algumas instruções de determinadas atividades, pois a criança aparentava ter incertezas sobre como proceder. Tal questão foi percebida principalmente na atividade do Desafio dos Opostos e no Pulando Asteroides. Em ambos os casos, a criança teve dificuldade em perceber a mudança de ação demandada durante as jogadas inibitórias. Na primeira atividade, ela não conseguia perceber a mudança de botão/asteroide, além de ficar com a impressão de que a regra da palavra dita na jogada se mantinha para a jogada seguinte. Na outra, a criança não conseguia identificar que seu "pulo" não havia sido validado e, por consequência, a jogada não seria validada. Para contornar estes problemas, a equipe acrescentou um tempo fixo entre as jogadas do Desafio dos Opostos e reforçou o feedback visual sobre o botão pressionado, evitando que se confundisse nesse aspecto.

Para o Pulando Asteroides a equipe acrescentou um quadro que informa quando o pulo foi "validado" pelo jogo. Além destes dois, também foram necessárias alterações na atividade do Túnel Acelerador de Partículas, onde a equipe percebeu que a criança não conseguia executar as jogadas em tempo, ainda que conseguisse ter a noção espacial correta, deslocando-se para a direita para mover o personagem para a esquerda, como a atividade exigia. Neste caso, foram acrescentadas flechas que indicam a localização dos obstáculos quando os mesmos se encontram fora do campo de visão do jogador.

\section{Considerações Finais}

Cientes de que melhorar/estimular as $\mathrm{FE}$ precocemente em crianças pode trazer benefícios a curto e longo prazo para o seu desenvolvimento, reflete-se o quanto é necessário investir em intervenções voltadas para a estimulação desse processo cognitivo. Dessa forma, o trabalho em questão apresenta a validação de um Exergame que exercita as FE, mais especificamente, o controle inibitório em crianças no Ensino Fundamental I. O presente projeto oportuniza o desenvolvimento de um Exergame para 
ser utilizado em uma intervenção de estimulação. Esta proposta justifica-se primeiramente pela demanda de um programa inovador, com técnicas aprimoradas e apoiadas na compreensão acerca do desenvolvimento cognitivo na infância e adolescência. Possibilita, ainda, a utilização de atividades compatíveis com a faixa de desenvolvimento cognitivo esperado para cada idade e fase escolar.

Neste contexto, a realização da avaliação do Exergame intitulado "As Incríveis Aventuras de Apollo e Rosetta no Espaço" demonstrou a combinação de técnicas de avaliação, sendo a primeira feita por meio de especialistas e uma segunda através de testes com usuário. Essa avaliação permitiu, além de avaliar a jogabilidade, observar se as atividades eram adequadas às crianças do Ensino Fundamental I, realizando a estimulação pretendida. Após realizar a avaliação, os autores analisaram os dados e conduziram uma série de alterações no Exergame, conforme descrito nas seções anteriores. Em seguida pretende-se realizar, junto às escolas, um programa de intervenção de estimulação para a comunidade estudantil, através da utilização deste Exergame de estimulação cognitiva. O mesmo deverá ser validado, desta forma, com mais crianças e adaptado às necessidades gerais encontradas. Adicionalmente, estudos futuros sobre aplicabilidade clínica em diferentes transtornos do neurodesenvolvimento serão muito interessantes e úteis para a saúde mental e educação.

\section{Referências}

BULL, R.; ESPY, K. A.; WIEBE, S. A. (2008) Short-term memory, working memory, and executive functioning in preschoolers: Longitudinal predictors of mathematical achievement at age 7 years. Developmental neuropsychology, Taylor \& Francis, v. 33, n. 3, p. 205-228.

DIAMOND, A. (2013) Executive functions. Annual review of psychology, NIH Public Access, v. 64, p. 135.

DIAMOND, A. (2015) Effects of physical exercise on executive functions: going beyond simply moving to moving with thought. Annals of sports medicine and research, NIH Public Access, v. 2, n. 1, p. 1011.

FINCO, M. D.; REATEGUI, E.; ZARO, M. A.; SHEEHAN, D. D.; KATZ, L. (2015) Exergaming as an alternative for students unmotivated to participate in regular physical education classes. International Journal of Game-Based Learning (IJGBL), IGI Global, v. 5, n. 3, p. 1-10.

FONSECA, R.; SILVA, P.; SILVA, R.. (2013) Acordo inter-juízes: O caso do coeficiente kappa. Laboratório de Psicologia 5.1: 81-90.

LEWIS, C. (1982). Using the thinking-aloud" method in cognitive interface design. IBM TJ Watson Research Center.

MOSSMANN, J. B. et al. Evaluation of the Usability and Playability of an Exergame for Executive Functions Stimulation and Its Development Process. Springer, Cham, p. 164-179, jul 2017. $<$ http://link.springer.com/10.1007/978-3-319-58472-0_14>.

PINTO, A. B. (2008) Desenvolvimento das funções executivas em crianças dos 6 aos 11 anos de idade. Tese (Doutorado) - Universidade do Porto, Porto.

WELSH, J. A.; NIX, R. L.; BLAIR, C.; BIERMAN, K. L.; NELSON, K. E. (2010) The development of cognitive skills and gains in academic school readiness for children from low-income families. Journal of educational psychology, American Psychological Association, v. 102, n. 1, p. 43. 